\title{
COVID-19 IMPACT ON DEVELOPMENT OF RENEWABLE ENERGY FACILITIES IN RURAL REGIONS IN EU
}

\author{
Vladislav Zavadskiy ${ }^{1}$, Gita Revalde ${ }^{2}$ \\ ${ }^{1}$ Almaty University of Power Engineering and Telecommunication, Kazakhstan; \\ ${ }^{2}$ Riga Technical University, Latvia \\ vladislav.zavadskiy@gmail.com, gita.revalde@rtu.lv
}

\begin{abstract}
The paper presents an overview of the COVID-19 impact and related trends with the development of the renewable energy facilities in the rural regions of the EU and globally. A short summery of the pre-pandemic situation with the available renewables and their potential development based on the publicly available sources in the rural regions of the EU is presented. Development of the renewable energy facilities in the rural regions will be considered as the correlations with the migration trends change after 2020. Migration analysis and the potential demand for the renewable energy will be calculated for the specific region, as well as the renewable energy capacity potential of the region. Technical barriers with the renewable energy development in such situation will be highlighted. The proposed problem solution studied in the paper and shortlisted: renewable energy sources (RES) type should be selected based on the regional features; industrial energy storage system should be applied; grid interconnection and unit commitment problem are critical to be solved. We found that the COVID impact should boost the renewable energy development in the rural regions in the EU, but such growth cannot be realized without the technical problem solving and proactive governmental support.
\end{abstract}

Keywords: COVID-19, migration trends, renewable energy, rural regions, grid connection, unit commitment, energy storage.

\section{Introduction}

Last year was the year of global changes and new challenges. The pandemic has affected absolutely all spheres of society, leaving no chance for the preservation of the old way of life. The restrictions not only directly affected the processes, but also changed many trends that will reinforce the changes. Influences on some processes entail far-reaching changes in other, unrelated areas. Revealing such changes is the goal of our research.

We assumed that the restrictions associated with the pandemic, namely, the transfer of employees to remote work, students to remote learning, would lead to a change in the trends of internal migration. Cities will become less attractive for life and work, and, accordingly, part of the population will move to rural areas. Accordingly, the load on the infrastructure of rural regions will increase, which will inevitably lead to an increase in energy consumption.

In view of the fact that recently the focus has been on the energy supply of cities, the rural regions did not receive proper development in this direction.

The energy industry is a rather inert industry, and changes associated with the need to provide additional energy sources, according to our assumptions, can occur quite quickly, therefore the most likely candidates for such a role are renewable energy sources.

To determine this opportunity, we needed to study migration trends and draw conclusions about the possible need for additional capacity. Then it was necessary to assess the availability of potential for renewable sources in the region and the possibilities for its implementation, the barriers to this.

Since the data on migration trends for the past year are at the stage of calculation and are not always available on public resources, we had to make an indirect assessment of trends using the example of other regions in the world and apply the information obtained to the regions of Europe, making the proviso that the numerical values may change.

Modeling the correlation between population migration, growing demand for electricity in rural areas and calculating the potential of renewable energy sources was carried out using the example of Latvia.

\section{Materials and methods}

\subsection{Regional and global migration trends}

From 2000 the trend of internal migration in Latvia has been aimed at the outflow of the population from rural areas to cities (Fig. 1) [1]. In total, in 2019 the rural population in Latvia reached 608.174 thousand people [1]. 


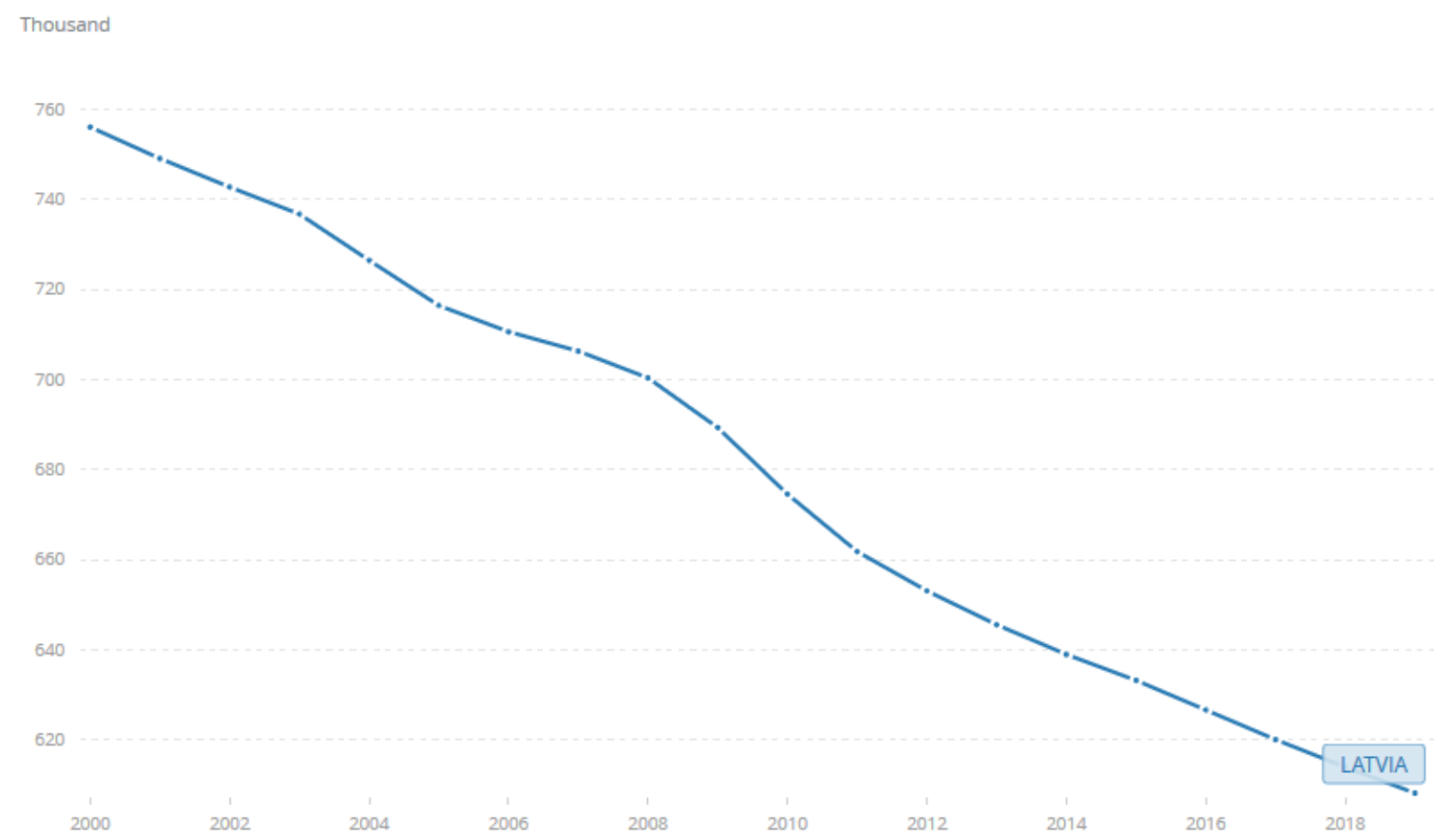

Fig. 1. Previous trend of rural population decrease in Latvia [1]

Year 2020 showed us a different picture. For instance, in India pandemic was the reason of unemployment rate increase. About 24 million rural households demanded work in August 2020, which is a $66 \%$ increase from August 2019 [2]. As a result, it is $21 \%$ increase in the sowing of Kharif crop across India, also even small farmers started to use their land [2]. [3].

For Australia the year 2020 brings a record of moving people from cities to rural places (Fig. 2)

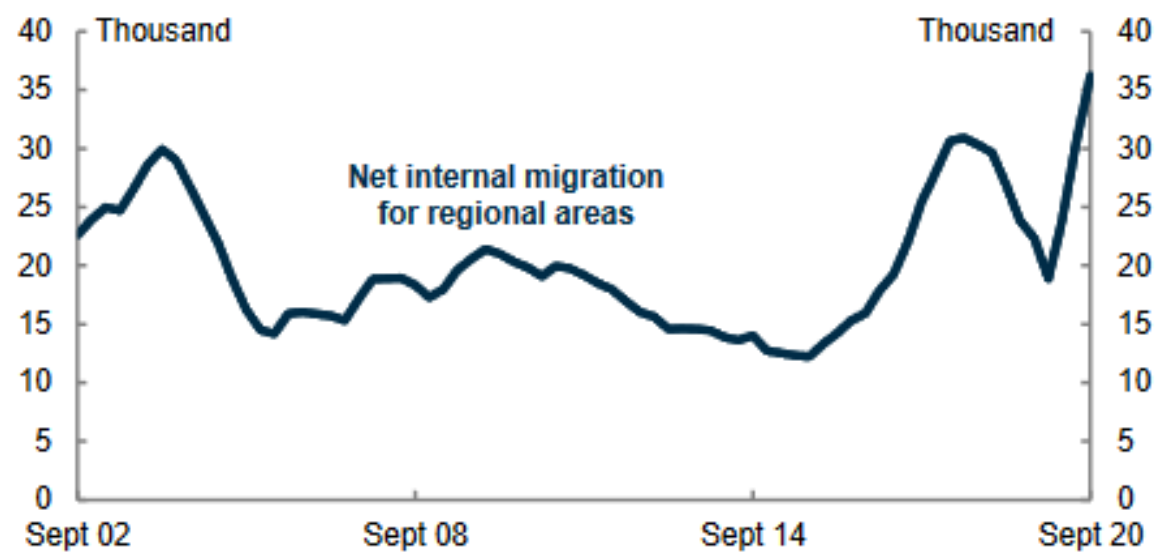

Fig. 2. Net internal migration for regional areas in Australia [3]

According to the research [4], 12.3\% of the population more likely will change their living place.

Migration to the rural places is possible due to the 'work from home' concept. The research [5] shows that in Europe the theoretical maximum share of such work places can be reached up to $46 \%$ without losing productivity.

In Latvia, the share of teleworking in 2020 reached 37\% (Fig. 3) [6]

In our study, we used the method of correlation analysis of statistical data with the assumption of a direct correlation between the increase in the number of inhabitants of rural regions and the growth of energy consumption.

Based on statistics from other regions of the world, we hypothesized a scenario where growth of the value of energy consumption in the rural regions in Latvia can reach $20 \%$, which should be covered with renewable energy sources. 


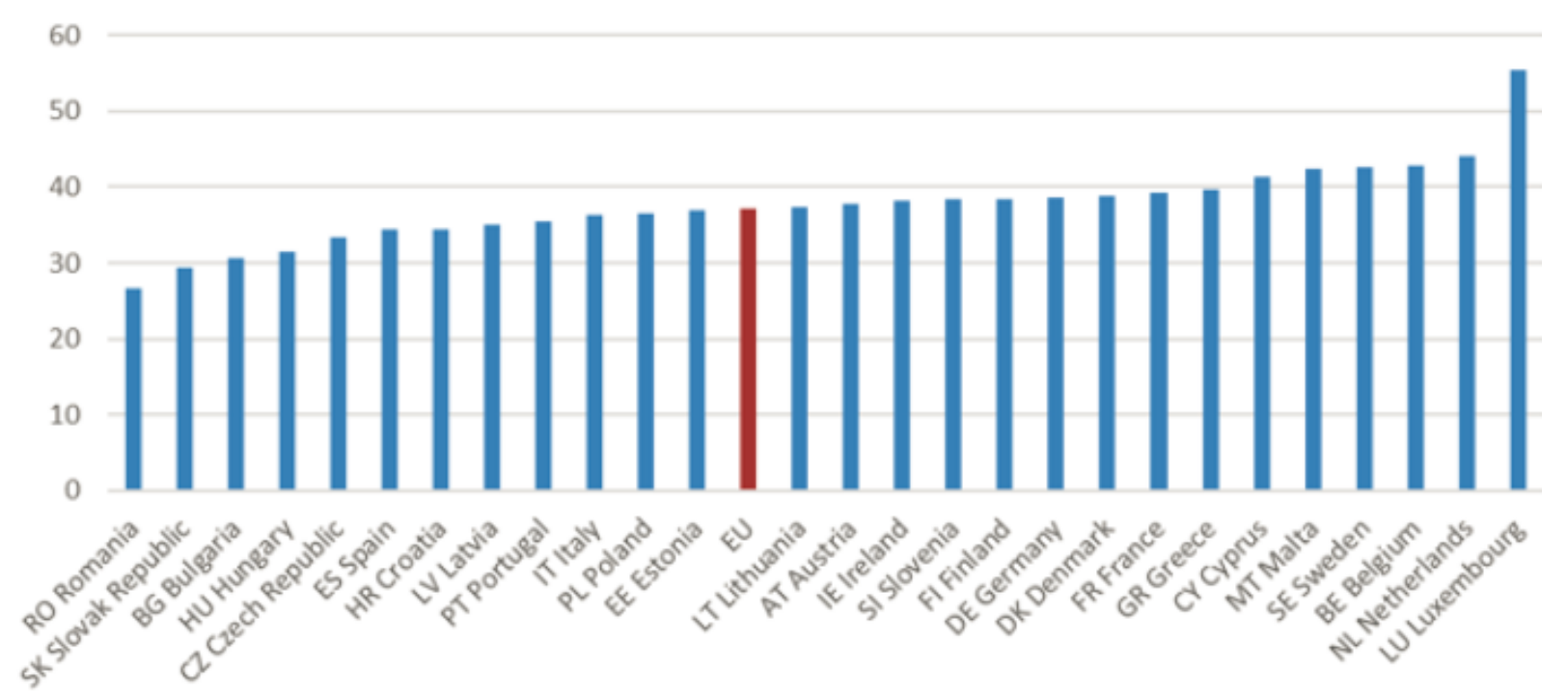

Fig. 3. Share of 'working from home' employees in EU [6]

Renewable energy sources and unit commitment

Due to unstable generation from the renewable energy sources, it is important to provide a backup by having a line interconnection between renewable facilities and electrical grid, as well as presenting traditional power sources in the system. But such approach will create a task of solving a unit commitment problem. [7].

Unit commitment problem is an optimization problem used to determine the operation schedule of the generating units at every hour interval with varying loads under different constraints and environments [8].

A lot of methods and approaches are used to solve the unit commitment problem: Priority List (PL), Dynamic Programming (DP), Branch-Bound, Mixed Integer Programming (MIP), Lagrangian Relaxation (LR) [9].

Another possible solution of smoothing the generation profile is usage of industrial storage batteries. But even till the present time electricity accumulation in huge amounts is a hard task [7].

\section{Results and discussion}

According to the analysis, there is no doubt that the migration trend was changed. Cities are not so attractive for the employees anymore. Big share of companies introduced teleworking approach and workers stayed in the rural arears for distance work. That created additional energy demand, which was assumed as $20 \%$ in our case.

For example, in Vidzeme region of Latvia electricity consumption in households is $163 \mathrm{GWh}$ [10]. With a possible increase of $20 \%$ the value goes to $195.6 \mathrm{GWh}$. So, we need to cover extra $32 \mathrm{GWh}$ of the possible increased generation capacity.

The wind energy potential in Latvia can be calculated using the Global Wind Atlas [11]. Mean wind power density map for $50 \mathrm{~m}$ heights is represented below (Fig. 4) [11].

The average wind potential value is about $300 \mathrm{~W} \cdot \mathrm{m}^{-2}$. With such output 106 square kilometers will be required to use for wind generation.

The solar energy potential in Latvia can be calculated using the Global Solar Atlas [12]. Photovoltaic power output potential is represented below (Fig. 5) [12].

The average solar potential value is about $2800 \mathrm{~W} \cdot \mathrm{m}^{-2}$. With such output 11.4 square kilometers will be required to use for solar generation.

Such values are the possible theoretical potential according to the represented sources. 


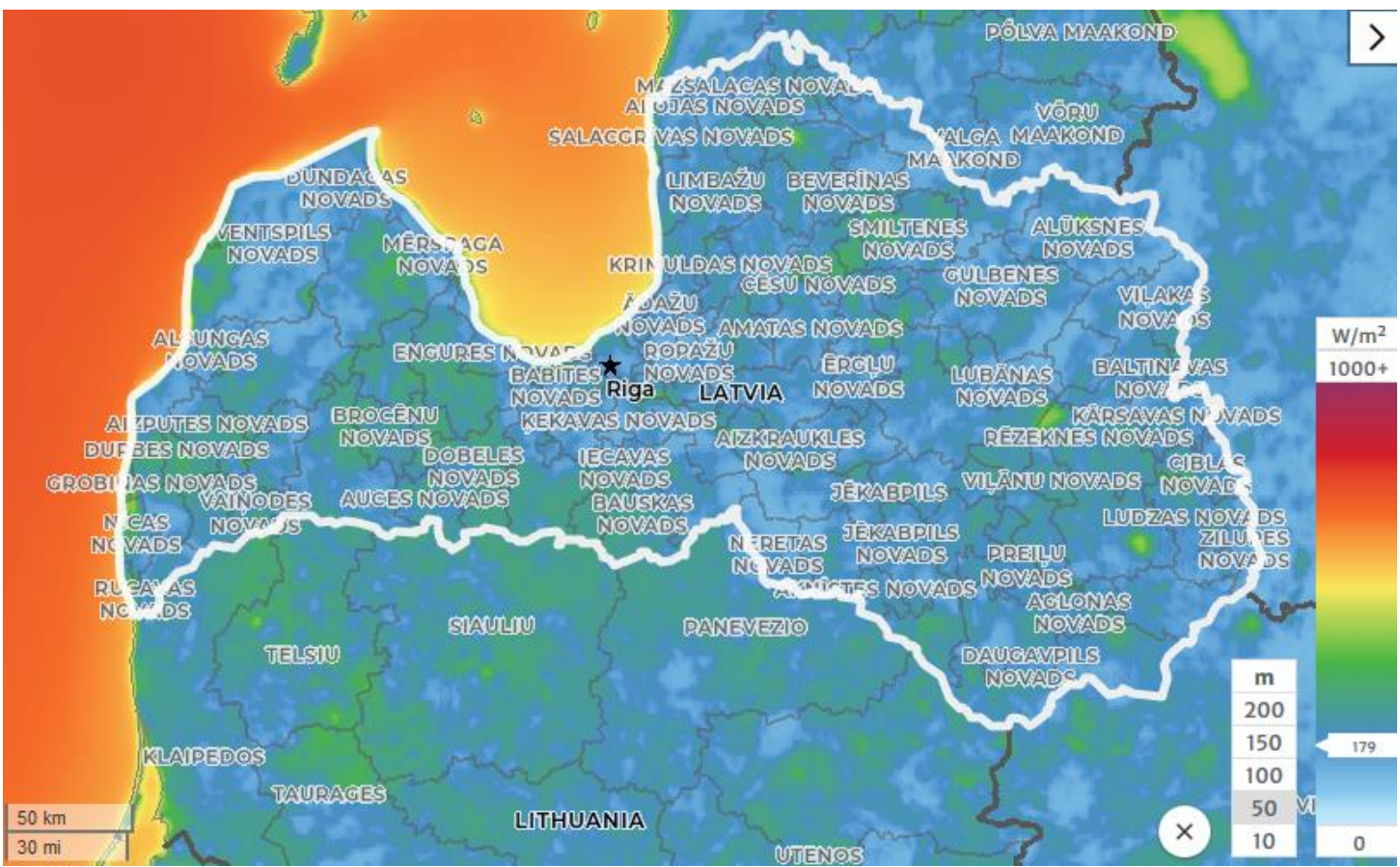

Fig. 4. Mean wind power density map for $50 \mathrm{~m}$ heights [8]

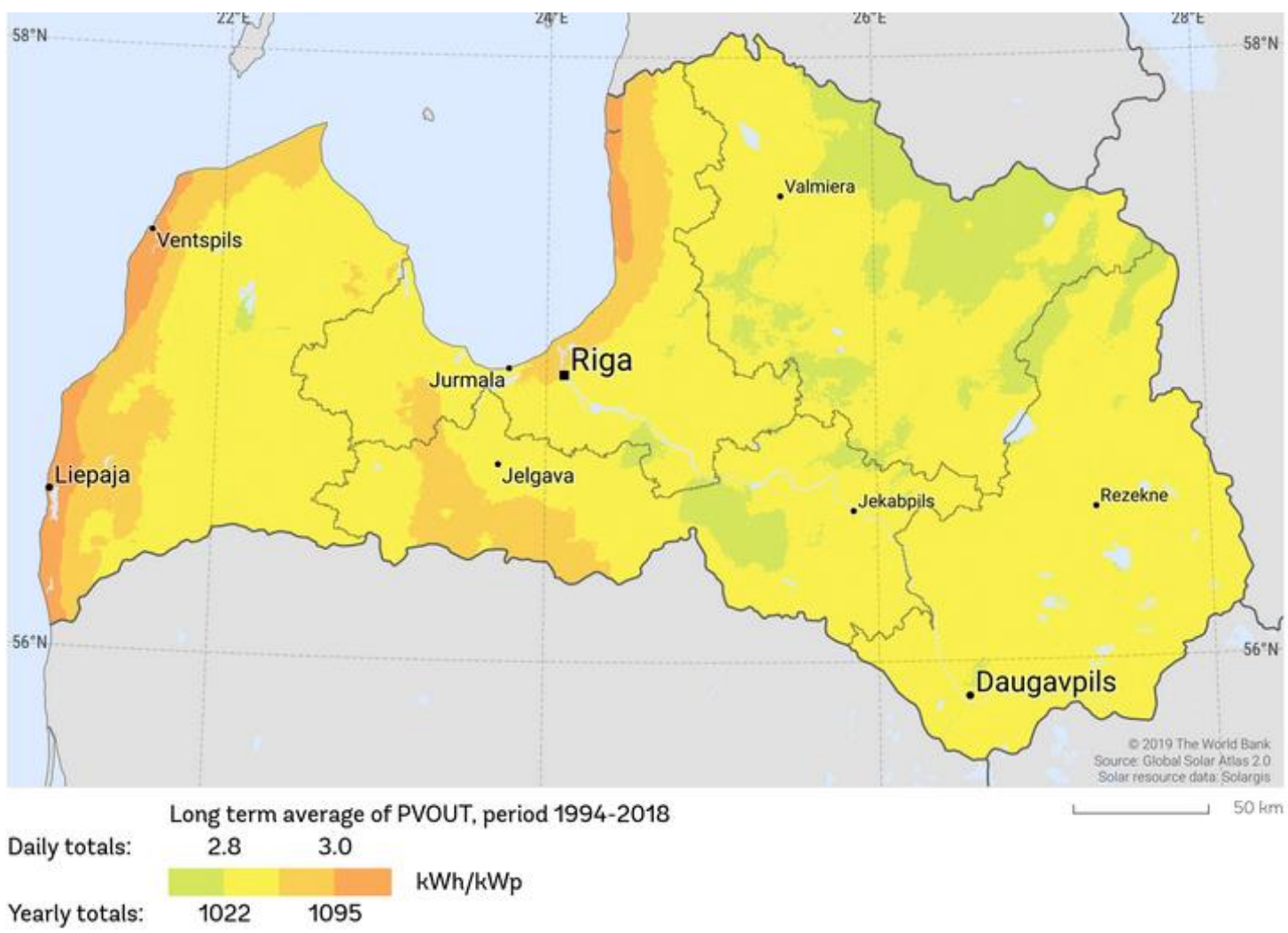

Fig. 5. Photovoltaic power output potential [9]

By doing a simulation we got a result that such value can be covered by installing wind or solar generation facilities in rural regions. From the land saving point of view solar generation is more attractive, but wind has less interuptions in the generation process according to its nature.

Introducing a big share of the renewables into a system, we need to be sure of the right dispatching and solving the unit commitment problem. This problem should be solved by using a common approach in a distributed electrical system [1].

Adding an electrical storage facility will provide more stability to the system. 


\section{Conclusions}

COVID-19 definitely changed our lives. Before 2020 no one could suppose that rural-urban migration trend will stop, and people will look for a possibility of staying in the rural areas. Migration processes are still being analyzing, but the first results worldwide show that at least $20 \%$ of people will stay in rural places what will increase the electricity consumption.

Undeveloped rural generation structures required fast and innovative solutions. Introducing renewables could be a good choice.

On the example of Latvia's rural arears we showed that it can be done. By using wind and solar generation capacities the increased demand can be covered.

But introducing a $20 \%$ share of renewables required a unit commitment problem solving and adding an electricity storage system.

There are data about migration, but there is a lack of reliable, comparable, and comprehensive data sources about rural-urban migration and energy consumption in 2020, especially in the EU countries. This should be covered with future research.

\section{References}

[1] Rural population in Latvia, World bank. [online] [25.03.2021]. Available at: https://data.worldbank.org/indicator/SP.RUR.TOTL $?$ end $=2019 \&$ locations $=$ LV\&start $=2000 \&$ view $=$ chart.

[2] COVID-19 Reverse Migration Calls for Long-Term Rural Development Planning, The Wire. [online] [25.03.2021]. Available at: https://thewire.in/rights/covid-19-reverse-migration-longterm-rural-development-planning.

[3] Migration between cities and regions: A quick guide to COVID-19 impacts, Australian Government center for population. [online] [25.03.2021]. Available at: https://population.gov.au/research/research-migration-between-cities-and-regions-a-quick-guideto-covid-19-impacts.html.

[4] Anticipating the impact of COVID-19 on internal migration. University of Queensland for the Centre for Population. Australian Government, December 2020. [online] [25.03.2021]. Available at: https://population.gov.au/docs/anticipating_the_impact_of_covid19_on_internal_migration.pdf.

[5] What's next for remote work: An analysis of 2,000 tasks, 800 jobs, and nine countries, McKinsey \&Company. [online] [25.03.2021]. Available at: https://www.mckinsey.com/featuredinsights/future-of-work/whats-next-for-remote-work-an-analysis-of-2000-tasks-800-jobs-andnine-countries\#.

[6] Milasi S., Bisello M., Hurley J., Sostero M., Fernández-Macías E. The potential for teleworking in Europe and the risk of a new digital divide. [online] [26.03.2021]. Available at: https://voxeu.org/article/potential-teleworking-europe-and-risk-new-digital-divide.

[7] Vladislav Zavadskiy, Unit Commitment in a dispersed power system involving renewable energy. LAP LAMBERT Academic Publishing, ISBN-13:978-3-659-82615-3; ISBN-10:3659826154; EAN:9783659826153, 2018.

[8] Saravanan B., Sikrid S. D., Kothari P., A solution to the unit commitment problem - a review. Front. Energy, vol. 7(2), 2013, pp. 223-236.

[9] Chandram K., Subrahmanyam N., Sydulu M., Unit Commitment by improved pre-prepared power demand table and Muller method. Electrical Power and Energy Systems, no. 33, 2011, pp. 106-114.

[10] Regional Energy Profile -Vidzeme Planning Region, PANEL 2050 -Partnership for New Energy Leadership 2050 Deliverable 3.1. [online] [26.03.2021]. Available at: https://ceesen.org/wpcontent/uploads/2018/03/Regional-Energy-Profile-Vidzeme-Planning-Region-Latvia.pdf .

[11]DTU Wind Energy, Department of Wind Energy, Global Wind Atlas. [online] [27.03.2021] http://globalwindatlas.com/index.html.

[12] The World Bank Group, Global Solar Atlas. [online] [27.03.2021]. Available at: http://globalsolaratlas.info/about. 